\title{
Intra-abdominal pressure and abdominal perfusion pressure in cirrhotic patients with septic shock
}

\author{
Hasan M Al-Dorzi ${ }^{1}$, Hani M Tamim², Asgar H Rishu', Abdulrahman Aljumah, Yaseen M Arabi ${ }^{1 *}$
}

\begin{abstract}
Background: The importance of intra-abdominal pressure (IAP) and abdominal perfusion pressure (APP) in cirrhotic patients with septic shock is not well studied. We evaluated the relationship between IAP and APP and outcomes of cirrhotic septic patients, and assessed the ability of these measures compared to other common resuscitative endpoints to differentiate survivors from nonsurvivors.

Methods: This study was a post hoc analysis of a randomized double-blind placebo-controlled trial in which mean arterial pressure (MAP), central venous oxygen saturation $\left(\mathrm{S}_{\mathrm{CVO}} \mathrm{O}_{2}\right)$ and IAP were measured every $6 \mathrm{~h}$ in 61 cirrhotic septic patients admitted to the intensive care unit. APP was calculated as MAP - IAP. Intra-abdominal hypertension (IAH) was defined as mean IAP $\geq 12 \mathrm{mmHg}$, and abdominal hypoperfusion as mean APP $<60 \mathrm{mmHg}$. Measured outcomes included ICU and hospital mortality, need for renal replacement therapy (RRT) and ventilator- and vasopressor-free days.

Results: IAH prevalence on the first ICU day was $82 \%$, and incidence in the first 7 days was $97 \%$. Compared to patients with normal IAP, IAH patients had significantly higher ICU mortality (74.0\% vs. 27.3\%, $p=0.005)$, required more RRT (78.0\% vs. $45.5 \%, p=0.06)$ and had lower ventilator- and vasopressor-free days. On a multivariate logistic regression analysis, IAH was an independent predictor of both ICU mortality (odds ratio (OR), 12.20; 95\% confidence interval $(C \mathrm{Cl}), 1.92$ to $77.31, p=0.008)$ and need for RRT (OR, 6.78; $95 \% \mathrm{Cl}, 1.29$ to $35.70, p=0.02)$. Using receiver operating characteristic curves, IAP (area under the curve (AUC) $=0.74, p=0.004$ ), APP (AUC $=0.71, p=$ 0.01), Acute Physiology and Chronic Health Evaluation II score (AUC $=0.71, p=0.02$ ), but not MAP, differentiated survivors from nonsurvivors.
\end{abstract}

Conclusions: IAH is highly prevalent in cirrhotic patients with septic shock and is associated with increased ICU morbidity and mortality.

\section{Background}

Cirrhotic patients with septic shock (SS) represent a unique group with different presentation, pathophysiology and prognosis compared to other critically ill patients [1-6]. Because of the presence of ascites [7], which is often complicated by spontaneous bacterial peritonitis [8], increased intra-abdominal pressure (IAP) occurs frequently in these patients. Studies have demonstrated that intra-abdominal hypertension (IAH) is common in critically ill patients $[9,10]$ and is associated with

\footnotetext{
* Correspondence: yaseenarabi@yahoo.com

'Department of Intensive Care Medicine, King Saud bin Abdulaziz University for Health Sciences, King Abdulaziz Medical City, Riyadh, 11426, Saudi Arabia Full list of author information is available at the end of the article
}

multiple organ dysfunction [11-14] and increased mortality [15]. Additionally, liver dysfunction is a significant IAH risk factor in these patients [16]. In cirrhotic patients, Luca et al. found that mechanically increasing IAP in 14 patients with portal hypertension led to deleterious effects such as increased azygos blood flow and decreased cardiac output and hepatic blood flow [17]. However, little is known about the clinical significance of IAH in critically ill cirrhotic patients. Moreover, it is not clear whether abdominal perfusion pressure (APP) is a good resuscitation endpoint in cirrhotics.

Therefore, we studied the occurrence of IAH in cirrhotic patients admitted with SS both on admission and during the intensive care unit stay and assessed its

\section{SpringerOpen ${ }^{\circ}$}

(C) 2012 Al-Dorzi et al.; licensee Springer This is an open access article distributed under the terms of the Creative Commons Attribution License (http://creativecommons.org/licenses/by/2.0), which permits unrestricted use, distribution, and reproduction in any medium, provided the original work is properly cited. 
association with mortality. The ability of IAP and APP compared to other commonly used resuscitation endpoints to differentiate survivors from nonsurvivors was also assessed.

\section{Methods}

\section{Patients and setting}

This study was conducted in a 21-bed closed medicalsurgical ICU of a tertiary care hospital with an active liver transplant service. The ICU was staffed $24 / 7$ by board-certified intensivists. In 2007, there were 1,118 ICU admissions with a mean Acute Physiology and Chronic Health Evaluation (APACHE) II score [18] of 24.4 and an APACHE II-adjusted standardized mortality ratio of 0.97 . This study was a post hoc analysis of a randomized double-blinded placebo-controlled trial that studied the effect of low-dose hydrocortisone on the outcomes of cirrhotic patients admitted to the ICU with SS. The trial, performed between April 2004 and October 2007, included 75 adult patients and was approved by the hospital's Institutional Review Board [19]. It excluded patients who had hypovolemic or hemorrhagic shock, known adrenal insufficiency, prior steroid use or contraindication for steroids [19]. It showed that hydrocortisone improved hemodynamics, but not mortality, and was associated with increased side effects [19]. The current study included the 61 patients who had repeated IAP measurements.

\section{IAP measurement}

The standard method for indirectly measuring IAP is to measure the intra-vesicular pressure [20]. For the clinical trial, IAP was measured by trained critical care nurses using the modified Kron technique [21] every 6 $\mathrm{h}$ for up to 7 days after ICU admission. Briefly, the bladder drainage system was clamped just distal to the connection of the urinary catheter to the drainage bag. An 18 -gauge needle was then inserted into the sampling port and connected via a sterile tube to the pressure transducer using two three-way stopcocks. A standard infusion bag of normal saline was attached to one stopcock, and a 60-ml syringe was connected to the second stopcock. Sterile saline (50 to $100 \mathrm{ml}$ ) was injected into the bladder. Measurements were taken at end-expiration while patients were in complete supine position and with the transducer zeroed at the symphysis pubis level.

\section{Patient management}

Patients were managed using a goal-directed therapy for the treatment of septic shock [22]. This entailed achieving mean arterial pressure (MAP) $\geq 65 \mathrm{mmHg}$, central venous pressure $(\mathrm{CVP}) \geq 8 \mathrm{mmHg}$ and central venous oxygen saturation $\left(\mathrm{ScvO}_{2}\right) \geq 70 \%$ using fluids, vasopressors, inotropes and/or blood transfusion. No goals were set for IAP and APP such that the management of IAH was left to the discretion of the attending intensivist.

\section{IAH definitions}

The World Society of the Abdominal Compartment Syndrome (http://www.wsacs.org), in its latest consensus statement [23], defined IAH as sustained or repeated IAP of $\geq 12 \mathrm{mmHg}$. Likewise, abdominal compartment syndrome (ACS) was defined as IAP > $20 \mathrm{mmHg}$ in combination with at least one new end-organ failure, which can be identified by a Sequential Organ Failure Assessment (SOFA) sub-score $\geq 3$ [23]. In this study, we calculated the mean of the first four IAP measurements done on each of the first 7 days of ICU stay. Patients with IAP $\geq 12 \mathrm{mmHg}$ were considered to have IAH. Those with IAP $\geq 20 \mathrm{mmHg}$ were considered to have ACS. In addition, APP was calculated by subtracting IAP from simultaneous MAP measurements. Mean APP $<60 \mathrm{mmHg}$ was considered abnormal [24].

\section{Collected data}

We collected the following demographic and clinical information: age, gender, body mass index, liver cirrhosis etiology, Child-Pugh score, admission APACHE II score, SOFA [25], presence of ascites on physical exam, diagnosis of spontaneous bacterial peritonitis and hepatic encephalopathy on ICU admission, admission hemoglobin, albumin, serum lactate, creatinine, bilirubin and ammonia, international normalized ratio (INR), the ratio of the partial pressure of arterial oxygen to the fraction of inspired oxygen $\left(\mathrm{PaO}_{2} / \mathrm{FiO}_{2}\right)$ and requirement for mechanical ventilation. We also extracted data on MAP, CVP, $\mathrm{ScvO}_{2}$, IAP and APP.

\section{Outcome measures}

The primary outcome measure was ICU mortality. The secondary outcomes were hospital mortality, ventilatorfree days, vasopressor-free days, duration of mechanical ventilation, ICU and hospital length of stay and the need for renal replacement therapy (RRT), including continuous veno-venous hemofiltration or intermittent hemodialysis. RRT was initiated at the discretion of the attending intensivist in consultation with the nephrology department.

\section{Statistical analysis}

Data were analyzed using SAS software (version 8.0; SAS Institute, Cary, NC, USA). Continuous data were presented as mean with standard deviation (SD), whereas categorical ones were summarized as absolute and relative frequencies (percent). Demographic and physiologic variables were compared among the different IAP groups using the Student's $t$ test or chi square/ Fisher's exact test based on whether the variable was 
continuous or categorical. Stepwise multiple logistic regression was used to study IAH predictors with the following independent variables: APACHE II score, presence of ascites and of encephalopathy, mechanical ventilation, number of transfused PRBC units on day 1, net fluid balance on day 1, INR and bilirubin. To examine the association between IAP and APP and different endpoints, we used multivariate logistic regression analysis to adjust for the following variables: age, APACHE II, Child-Pugh score, requirement for mechanical ventilation, creatinine, INR, fluid balance on day 1 and hydrocortisone therapy. Moreover, the ability of IAP and APP to discriminate survivors from nonsurvivors was compared to other standard hemodynamic endpoints (MAP and $\mathrm{ScvO}_{2}$ ) and APACHE II using the receiver operating characteristic (ROC) curves. Youden index was calculated to assess the best IAP and APP cut-offs that discriminate survivors from non survivors [26]. Additionally, survival analysis was performed using Kaplan-Meier curves to examine the time-dependent mortality difference stratified by different hemodynamic targets (MAP $\geq 65$ and $<65 \mathrm{mmHg}, \mathrm{ScvO}_{2} \geq 70 \%$ and $<70 \%$ and IAP and APP $\geq$ and $<$ the best cut-offs on the ROC curve analysis).

\section{Results}

\section{Prevalence and incidence of IAH and characteristics of} the patients according to IAH

The studied patients had the following characteristics (Table 1): age $=59.0 \pm 13.0$ years, $58 \%$ were men, hepatitis C was the most common cause of cirrhosis (44\%) with mean Child-Pugh score of 11.6 and most patients had ascites (94\%) and hepatic encephalopathy (76\%). All patients were on vasopressors, and most (90\%) required mechanical ventilation. On the first ICU admission day, mean IAP was $16.7 \pm 3.9 \mathrm{mmHg}$, with 50 patients $(82 \%)$ having IAH, and 9 patients (15\%) having ACS. In addition, $70 \%$ of patients had mean APP $<60 \mathrm{mmHg}$. During the first 7 days of ICU stay, $97 \%$ of patients developed IAH, and $39 \%$ had ACS.

The characteristics of the study population according to IAP (< 12 vs. $\geq 12 \mathrm{mmHg}$ ) and APP (< 60 vs. $\geq 60$ $\mathrm{mmHg}$ ) are shown in Table 1. On the stepwise logistic regression analysis, none of the studied variables was associated with $\mathrm{IAH}$, including fluid balance on day 1 (OR, 1.28/l increment; 95\% CI, 0.90 to 1.81 ).

\section{Hemodynamic endpoints}

Figure 1 describes four hemodynamic indices (MAP, $\mathrm{ScVO}_{2}$, IAP and APP) observed in the first 7 days of ICU admission. Whereas MAP $\geq 65 \mathrm{mmHg}$ and $\mathrm{ScvO}_{2} \geq 70 \%$ were achieved in most patients (e.g., $86 \%$ and $77 \%$ of patients, respectively, on day 2), IAP $<12 \mathrm{mmHg}$ and
APP $\geq 60 \mathrm{mmHg}$ were present in fewer patients $(23 \%$ and $36 \%$, respectively, on day 2). ICU survivors and nonsurvivors had similar day $1 \mathrm{ScvO}_{2}(75 \pm 8 \%$ and $78 \pm$ $11 \%$, respectively, $p=0.35)$ and MAP $(71 \pm 7 \mathrm{mmHg}$ vs. $70 \pm 7 \mathrm{mmHg}$, respectively, $p=0.42)$. On the other hand, ICU survivors had significantly lower day 1 IAP (13 \pm $4 \mathrm{mmHg}$ vs. $16 \pm 5 \mathrm{mmHg}, p=0.015)$ and higher APP (59 $\pm 7 \mathrm{mmHg}$ vs. $54 \pm 8 \mathrm{mmHg}, p=0.02$ ) compared to nonsurvivors.

\section{Relationship between IAH and outcomes}

The ICU and hospital mortality for all patients were $65.6 \%$ and $88.5 \%$, respectively. Table 2 describes the outcomes of patients according to the presence or absence of IAH on the first ICU day. Although the ICU length of stay was similar in both groups, IAH patients had significantly fewer vasopressor- and ventilator-free days than the non-IAH group and tended to require RRT more often $(78.0 \%$ vs. $45.5 \%, p=0.06)$. ICU mortality was almost three times higher in the IAH group $(74.0 \%$ vs. $27.3 \%, p=0.005)$. However, the hospital mortality was not statistically different between the two groups $(92.0 \%$ vs. $72.7 \%, p=0.10)$. The association between APP and outcomes followed a similar pattern but was not statistically different. Figure 2 describes the evolution of SOFA, $\mathrm{ScvO}_{2}$, IAP and APP in ICU survivors and nonsurvivors during ICU stay, and shows clear separation for the SOFA score, APP and, to a lesser extent, IAP, but not $\mathrm{ScvO}_{2}$.

For patients with IAP $<12 \mathrm{mmHg}$, ICU mortality was $50.0 \%$ for the hydrocortisone-treated group compared to $14.3 \%$ for the placebo group, $p=0.49$. In IAH patients, ICU mortality was $64.3 \%$ for the hydrocortisone-treated patients compared to $86.4 \%$ for the placebo group, $p=$ 0.08 . Randomization to either hydrocortisone or placebo did not affect ICU mortality for patients with APP < or $\geq 60 \mathrm{mmHg}$.

\section{IAP and APP as predictors of outcomes}

Stepwise multivariate logistic regression analysis (Table 3) showed that IAH was significantly associated with increased ICU mortality (OR, 12.20; 95\% CI, 1.92 to 77.31 , $p=0.008$ ) and need for RRT (OR, 6.78; 95\% CI, 1.29 to $35.70, p=0.02$ ), but not hospital mortality (OR, 6.83; 95\% CI, 0.86 to $54.12, p=0.07)$. The relationship between abdominal hypoperfusion (APP $<60 \mathrm{mmHg}$ ) and various outcomes did not reach statistical significance (Table 3).

\section{Resuscitation indices as predictors of ICU mortality}

Figure 3 shows the ROC curves of four resuscitation indices (MAP, $\mathrm{ScrO}_{2}$, IAP and APP) and APACHE II. Of the four indices, only IAP and APP had significant discrimination (areas under the curve 0.74 [95\% CI, 0.58 
Table 1 Characteristics of patients according to mean IAP and APP on the first ICU admission day.

\begin{tabular}{|c|c|c|c|c|c|c|c|}
\hline & $\begin{array}{l}\text { All patients } \\
\qquad N=61\end{array}$ & $\begin{array}{c}\mathrm{IAP}^{\mathrm{a}}<12 \\
\mathrm{mmHg} \\
N=11\end{array}$ & $\begin{array}{c}\mathrm{IAP}^{\mathrm{a}} \geq 12 \\
\mathrm{mmHg} \\
N=50\end{array}$ & $\begin{array}{c}p \\
\text { value }\end{array}$ & $\begin{array}{c}\mathrm{APP}^{\mathrm{a}} \geq 60 \\
\mathrm{mmHg} \\
N=18\end{array}$ & $\begin{array}{c}\mathrm{APP}^{\mathrm{a}}<60 \\
\mathrm{mmHg} \\
N=43\end{array}$ & $p$ value \\
\hline Age in years, mean $\pm S D$ & $59.8 \pm 12.2$ & $63.6 \pm 7.4$ & $59.0 \pm 13.0$ & 0.26 & $59.0 \pm 14.2$ & $60.2 \pm 11.5$ & 0.74 \\
\hline Male sex, $N(\%)$ & $36(59.0)$ & $7(63.7)$ & $29(58.0)$ & 1.00 & $7(38.9)$ & $18(41.9)$ & 0.83 \\
\hline Body mass index $\left(\mathrm{Kg} / \mathrm{m}^{2}\right)$, mean $\pm \mathrm{SD}$ & $26.8 \pm 5.9$ & $26.5 \pm 6.3$ & $26.9 \pm 5.9$ & 0.87 & $26.3 \pm 6.5$ & $27.0 \pm 5.8$ & 0.70 \\
\hline \multicolumn{8}{|l|}{ Etiology of liver cirrhosis, N (\%) } \\
\hline Hepatitis C & $30(49.2)$ & $8(73.0)$ & $22(44.0)$ & & $7(39.0)$ & $23(53.0)$ & \\
\hline Hepatitis B & $17(27.9)$ & $2(18.0)$ & $15(30.0)$ & 0.27 & $6(33.0)$ & $11(26.0)$ & 0.56 \\
\hline Others & $14(23.0)$ & $1(9.0)$ & $13(26.0)$ & & $5(28.0)$ & $9(21.0)$ & \\
\hline Child-Pugh score, mean \pm SD & $11.6 \pm 1.6$ & $11.2 \pm 1.4$ & $11.6 \pm 1.6$ & 0.39 & $11.2 \pm 1.9$ & $11.7 \pm 1.4$ & 0.29 \\
\hline APACHE I| score, mean \pm SD & $30.1 \pm 7.5$ & $23.9 \pm 7.7$ & $31.5 \pm 6.7$ & 0.002 & $29.9 \pm 7.8$ & $30.2 \pm 7.4$ & 0.91 \\
\hline SOFA score, mean \pm SD & $14.9 \pm 3.7$ & $12.5 \pm 4.5$ & $15.4 \pm 3.3$ & 0.02 & $13.9 \pm 3.7$ & $15.3 \pm 3.7$ & 0.1 \\
\hline SOFA renal sub-score & $2.2 \pm 1.4$ & $2.0 \pm 1.7$ & $2.3 \pm 1.3$ & 0.52 & $1.7 \pm 1.4$ & $2.5 \pm 1.3$ & 0.06 \\
\hline $\mathrm{SBP}, N(\%)$ & $19(31.1)$ & $7(63.6)$ & $12(24.0)$ & 0.03 & $5(27.8)$ & $14(32.6)$ & 0.71 \\
\hline Encephalopathy, N (\%) & $42(68.9)$ & $4(36.4)$ & $38(76.0)$ & 0.03 & $11(61.1)$ & $31(72.1)$ & 0.28 \\
\hline Ascites, $N(\%)$ & $58(95.1)$ & $11(100)$ & $47(94.0)$ & 0.05 & $16(88.9)$ & $42(97.7)$ & 0.26 \\
\hline Mechanically ventilated, $N(\%)$ & $51(83.6)$ & $6(54.5)$ & $45(90.0)$ & 0.01 & $16(88.9)$ & $35(81.4)$ & 0.71 \\
\hline $\mathrm{PaO}_{2} / \mathrm{FiO}_{2}$ ratio $(\mathrm{mmHg})$, mean $\pm \mathrm{SD}$ & $252 \pm 141$ & $261 \pm 129$ & $250 \pm 144$ & 0.83 & $194 \pm 117$ & $277 \pm 144$ & 0.04 \\
\hline $\begin{array}{l}\text { Norepinephrine dose at inclusion ( } \mu \mathrm{g} / \mathrm{kg} / \\
\mathrm{min}), \text { mean } \pm \mathrm{SD}\end{array}$ & $0.35 \pm 0.35$ & $0.20 \pm 0.29$ & $0.39 \pm 0.35$ & 0.11 & $0.26 \pm 0.34$ & $0.39 \pm 0.35$ & 0.21 \\
\hline Creatinine $^{b}(\mu \mathrm{mol} / \mathrm{l})$, mean $\pm \mathrm{SD}$ & $289 \pm 165$ & $299 \pm 176$ & $286 \pm 165$ & 0.81 & $239 \pm 147$ & $309 \pm 170$ & 0.13 \\
\hline $\mathrm{INR}$, mean $\pm \mathrm{SD}$ & $2.8 \pm 1.4$ & $2.6 \pm 1.5$ & $2.8 \pm 1.4$ & 0.71 & $2.4 \pm 0.7$ & $2.9 \pm 1.6$ & 0.08 \\
\hline Bilirubin $^{\mathrm{b}}(\mu \mathrm{mol} / \mathrm{l})$, mean $\pm \mathrm{SD}$ & $340.3 \pm 284.3$ & $146.0 \pm 193.5$ & $383.1 \pm 284.6$ & 0.01 & $313.3 \pm 305.2$ & $351.7 \pm 278.1$ & 0.63 \\
\hline Ammonia $^{\mathrm{b}}(\mu \mathrm{mol} / \mathrm{l})$, mean $\pm \mathrm{SD}$ & $110.2 \pm 101.1$ & $74.7 \pm 41.1$ & $118.0 \pm 108.8$ & 0.03 & $111.6 \pm 167.2$ & $109.6 \pm 57.4$ & 0.96 \\
\hline Albumin $(g / l)$, mean $\pm S D$ & $32.5 \pm 7.1$ & $33.8 \pm 8.1$ & $32.2 \pm 6.9$ & 0.50 & $31.5 \pm 5.4$ & $32.9 \pm 7.7$ & 0.48 \\
\hline Hemoglobin $(\mathrm{g} / \mathrm{dl})$, mean \pm SD & $8.6 \pm 1.6$ & $9.4 \pm 1.6$ & $8.4 \pm 1.6$ & 0.27 & $8.3 \pm 1.5$ & $8.7 \pm 1.6$ & 0.42 \\
\hline Lactate level $^{\mathrm{b}}(\mathrm{mmol} / \mathrm{l})$, mean $\pm \mathrm{SD}$ & $4.4 \pm 4.3$ & $3.7 \pm 4.6$ & $4.5 \pm 4.2$ & 0.59 & $2.9 \pm 2.2$ & $5.0 \pm 4.8$ & 0.02 \\
\hline Fluid intake in day $1(\mathrm{ml})$, mean \pm SD & $4,356 \pm 2,574$ & $3,993 \pm 1,877$ & $4,436 \pm 2,712$ & 0.61 & $4,015 \pm 2,486$ & $4,499 \pm 3,336$ & 0.51 \\
\hline Fluid balance in day $1(\mathrm{ml})$, mean $\pm \mathrm{SD}$ & $3,177 \pm 2,919$ & $1,544 \pm 2,980$ & $3,537 \pm 4,335$ & 0.04 & $2,368 \pm 2,913$ & $3,516 \pm 2,887$ & 0.16 \\
\hline MAP day $1(\mathrm{mmHg})$, mean $\pm \mathrm{SD}$ & $70.7 \pm 7.2$ & $58.8 \pm 5.8$ & $59.4 \pm 8.1$ & 0.83 & $63.3 \pm 7.1$ & $57.6 \pm 7.3$ & 0.007 \\
\hline CVP day $1(\mathrm{mmHg})$, mean $\pm \mathrm{SD}$ & $15.5 \pm 6.2$ & $12.3 \pm 4.0$ & $16.2 \pm 6.4$ & 0.054 & $14.1 \pm 6.5$ & $16.1 \pm 6.1$ & 0.28 \\
\hline IAP day $1(\mathrm{mmHg})$, mean \pm SD & $15.3 \pm 4.7$ & $9.0 \pm 2.2$ & $16.7 \pm 3.9$ & $<0001$ & $12.8 \pm 3.8$ & $16.3 \pm 4.7$ & 0.008 \\
\hline APP day $1(\mathrm{mmHg})$, mean $\pm \mathrm{SD}$ & $55.5 \pm 7.7$ & $59.4 \pm 6.2$ & $54.6 \pm 7.8$ & 0.06 & $64.7 \pm 5.4$ & $51.6 \pm 4.7$ & $<0.0001$ \\
\hline \multicolumn{8}{|l|}{ Randomization, N (\%) } \\
\hline Hydrocortisone & $32(52.5)$ & $4(36.4)$ & $28(56.0)$ & 0.24 & $14(77.8)$ & $18(41.9)$ & 0.01 \\
\hline Placebo & $29(47.5)$ & 7 (63.6) & $22(44.0)$ & & $4(22.2)$ & $25(58.1)$ & \\
\hline
\end{tabular}

IAP $\geq 12 \mathrm{mmHg}$ indicates intra-abdominal hypertension, and APP $<60 \mathrm{mmHg}$ indicates abdominal hypoperfusion. IAP, intra-abdominal pressure; APP, abdominal perfusion pressure; SD, standard deviation; APACHE, Acute Physiology and Chronic Health Evaluation; SOFA, Sequential Organ Failure Assessment; SBP, spontaneous bacterial peritonitis; $\mathrm{MAP}$, mean arterial pressure; $\mathrm{CVP}$, central venous pressure; INR, international normalized ratio; $\mathrm{PaO}_{2} / \mathrm{FiO}_{2}$, the ratio of the partial pressure of arterial oxygen $\left(\mathrm{PaO}_{2}\right)$ to the fraction of inspired oxygen $\left(\mathrm{FiO}_{2}\right)$. ${ }^{\mathrm{a}}$ Mean values on the first ICU day. ${ }^{\text {b}} \mathrm{To}$ convert creatinine to mg/dl, divide by 88.4 ; bilirubin to $\mathrm{mg} / \mathrm{dl}$, divide by 17.1 ; ammonia to $\mu \mathrm{g} / \mathrm{dl}$, divide by 0.587 ; lactic acid to $\mathrm{mg} / \mathrm{dl}$, divide by 0.111 .

to 0.90 ] and 0.71 [95\% CI, 0.56 to 0.85$]$, respectively) whereas MAP and $\mathrm{ScvO}_{2}$ did not. IAP $=12.4 \mathrm{mmHg}$ and APP $=54.7 \mathrm{mmHg}$ were found to be the cut-offs with the highest calculated Youden index (0.38 and 0.36, respectively) and, hence, the best to discriminate survivors from nonsurvivors.

Figure 4 describes the Kaplan-Meier curves of patients having the following resuscitation indices on the first ICU day (MAP $\geq 65$ vs. $<65 \mathrm{mmHg}, \mathrm{ScvO}_{2} \geq 70 \%$ vs. $<$ $70 \%$, IAP $\geq 12$ vs. $<12 \mathrm{mmHg}$ and APP $\geq 55$ vs. $<55$
$\mathrm{mmHg}$ ) and shows the presence of a significant survival difference based on IAP < 12 vs. $\geq 12 \mathrm{mmHg}$.

\section{Discussion}

The main findings of this study were the following: IAH was common in cirrhotic patients presenting with SS; IAH was an independent predictor for the need for RRT and of ICU mortality, and finally, IAP discriminated better between survivors and nonsurvivors than MAP and $\mathrm{ScrO}_{2}$. 


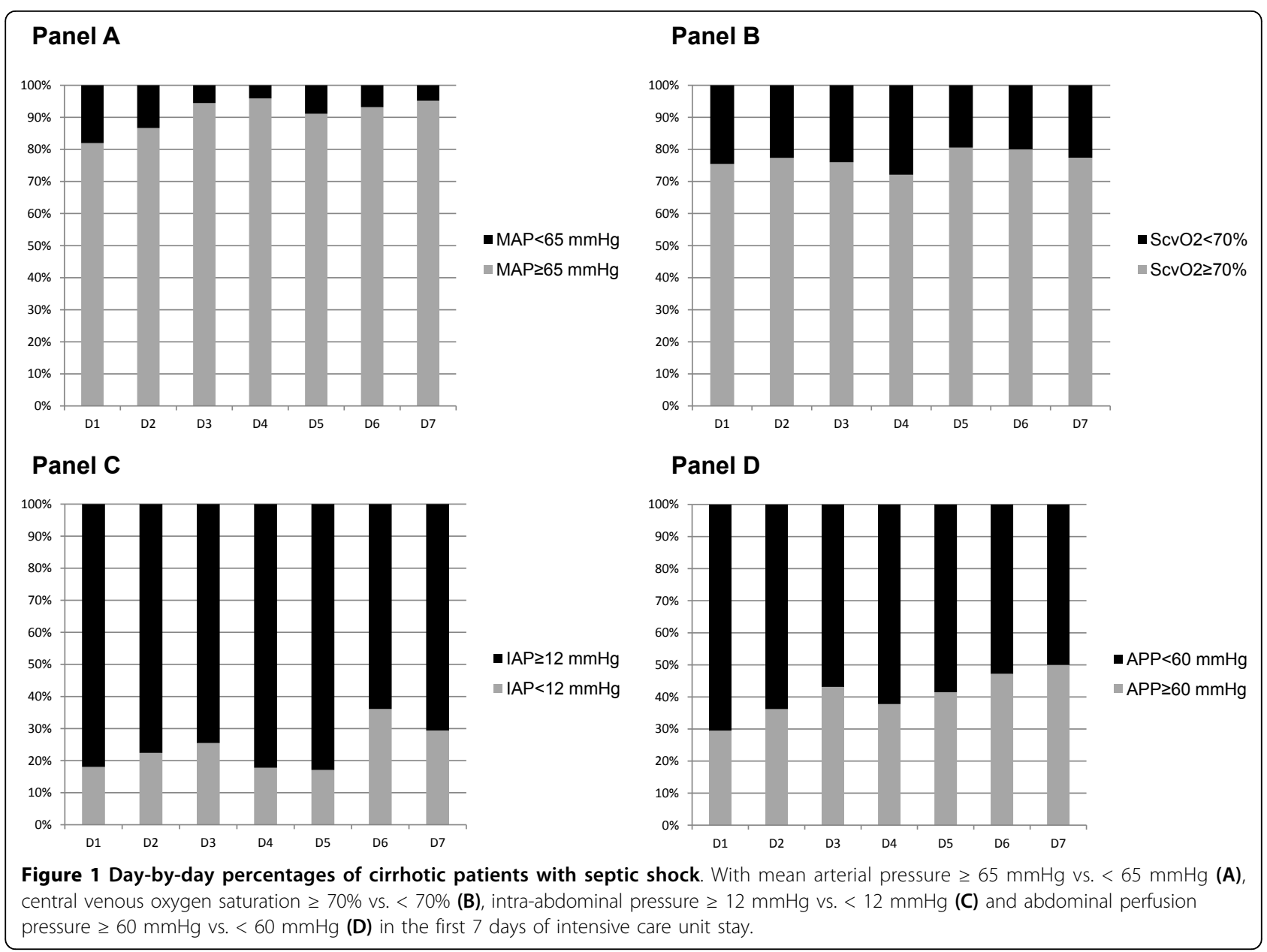

Literature on IAH in patients with liver cirrhosis is scarce. One study showed that mechanically increasing IAP by $10 \mathrm{mmHg}$ in 14 patients with portal hypertension led to a reduction in hepatic blood flow by $20 \%(p<0.05)$ [17]. Another study found that increased IAP leads to an increase in variceal pressure, radius, volume and wall tension, which may trigger variceal bleeding [27]. These findings suggest that increased IAP contributes to acute decompensation of liver function and to various cirrhosis-related complications, which support our findings.

In this study, IAH was defined as mean IAP $\geq 12$ $\mathrm{mmHg}$ at which physiologic and clinical derangements

Table 2 Outcomes of cirrhotic patients with septic shock according to the occurrence of intra-abdominal hypertension and abdominal hypoperfusion.

\begin{tabular}{|c|c|c|c|c|c|c|}
\hline & $\begin{array}{c}\mathrm{IAP}^{\mathrm{a}}<12 \mathrm{mmHg} \\
N=11\end{array}$ & $\begin{array}{c}\mathrm{IAP}^{\mathrm{a}} 1 \geq 12 \mathrm{mmHg} \\
N=50\end{array}$ & $p$ value & $\begin{array}{c}\mathrm{APP}^{\mathrm{a}} \geq 60 \mathrm{mmHg} \\
N=18\end{array}$ & $\begin{array}{c}\mathrm{APP}^{\mathrm{a}}<60 \mathrm{mmHg} \\
N=43\end{array}$ & $p$ value \\
\hline ICU mortality, N (\%) & $3(27.3)$ & $37(74.0)$ & 0.005 & $9(50)$ & $31(72.1)$ & 0.10 \\
\hline Hospital mortality, N (\%) & $8(72.7)$ & $46(92.0)$ & 0.10 & $15(83.3)$ & $39(90.7)$ & 0.41 \\
\hline Duration of MV in days, mean \pm SD & $4.8 \pm 7.5$ & $8.2 \pm 6.7$ & 0.14 & $9.6 \pm 7.1$ & $8.9 \pm 6.4$ & 0.70 \\
\hline Ventilator-free days, mean \pm SD & $15.3 \pm 11.4$ & $4.7 \pm 7.2$ & 0.01 & $7.4 \pm 8.7$ & $6.3 \pm 9.2$ & 0.65 \\
\hline Vasopressor-free days, mean \pm SD & $10.5 \pm 8.4$ & $4.6 \pm 7.1$ & 0.02 & $8.4 \pm 8.6$ & $4.5 \pm 7.1$ & 0.07 \\
\hline ICU LOS (days), mean \pm SD & $11.1 \pm 8.0$ & $9.8 \pm 6.0$ & 0.56 & $11.0 \pm 6.7$ & $9.6 \pm 6.2$ & 0.45 \\
\hline Hospital LOS (days), mean \pm SD & $31.1 \pm 16.8$ & $21.1 \pm 14.6$ & 0.05 & $23.6 \pm 10.3$ & $22.7 \pm 17.1$ & 0.81 \\
\hline Requirement for RRT, N (\%) & $5(45.5)$ & $39(78)$ & 0.06 & $11(61.1)$ & $33(76.7)$ & 0.21 \\
\hline RRT-free days, mean \pm SD & $10.8 \pm 12.7$ & $5.0 \pm 7.5$ & 0.17 & $7.4 \pm 8.9$ & $5.5 \pm 8.8$ & 0.44 \\
\hline
\end{tabular}

IAP $\geq 12 \mathrm{mmHg}$ indicates intra-abdominal hypertension, and APP $<60 \mathrm{mmHg}$ indicates abdominal hypoperfusion. IAP, intra-abdominal pressure; APP, abdominal perfusion pressure; RRT, renal replacement therapy; MV, mechanical ventilation; LOS, length of stay. ${ }^{a}$ Mean values on the first ICU day. 


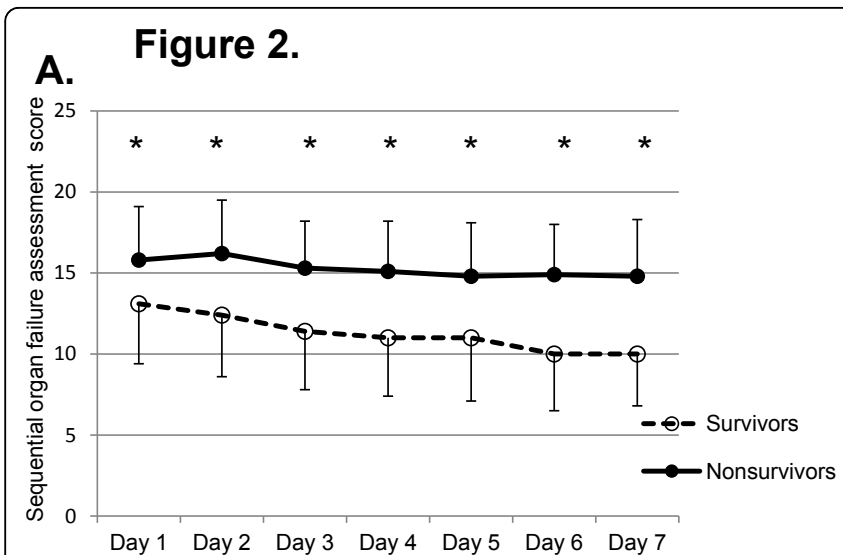

C.

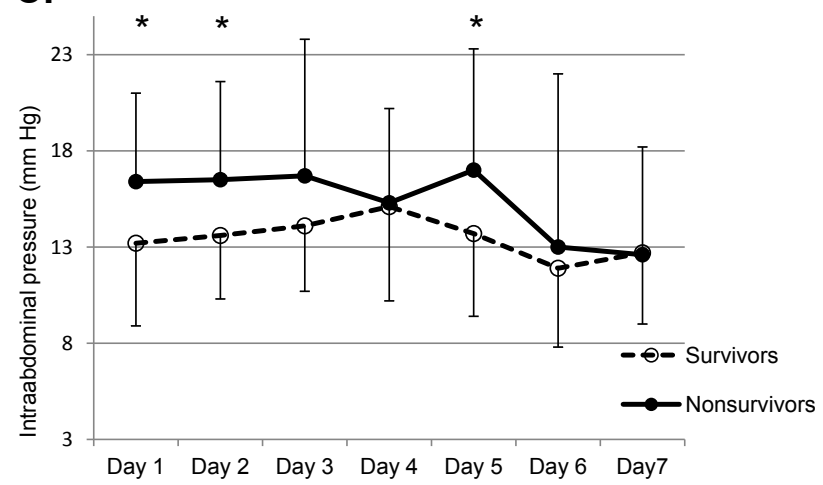

B.

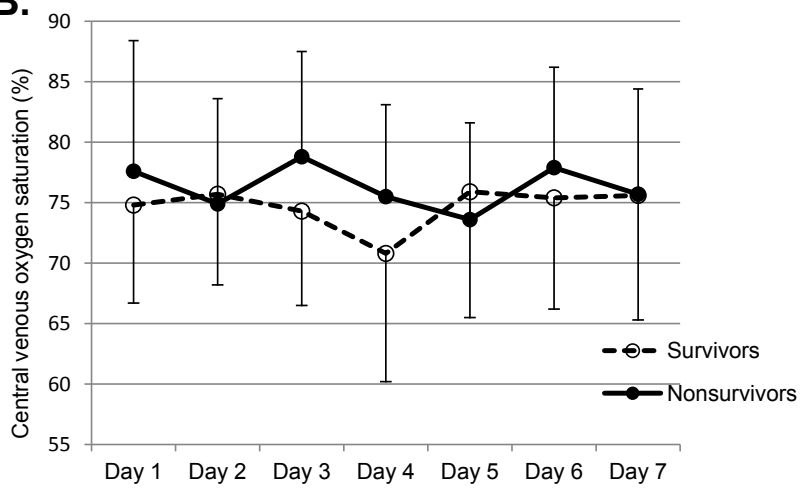

D.

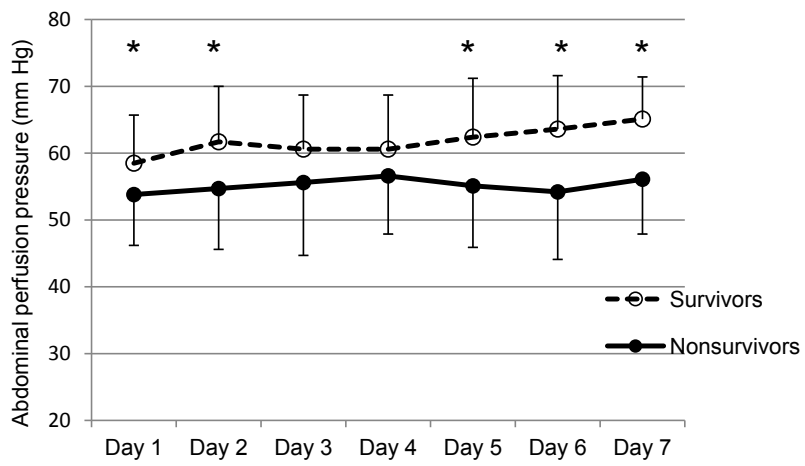

${ }^{*} p<0.05$

Figure 2 Evolution of the different variables studied. Sequential organ failure assessment score (A), central venous oxygen saturation (B), intra-abdominal pressure (C) and abdominal perfusion pressure (D) during the first 7 days of intensive care unit stay in ICU survivors and nonsurvivors. Error bars represent standard deviations.

usually occur [9,23]. APP $<60 \mathrm{mmHg}$ was considered as an indicator of abdominal hypoperfusion as this pressure has been shown to correlate well with survival from IAH and ACS [28]. This followed the recommendation of the International Conference of Experts on Intra-abdominal Hypertension and Abdominal Compartment Syndrome [24]. We found that $82 \%$ of cirrhotic patients with SS had IAH, and most patients (70\%) had reduced APP (< $60 \mathrm{mmHg}$ ) on the first ICU admission day. This is higher than the IAH prevalence in general ICU patients and could be explained by the high prevalence of ascites in cirrhotics. A multicenter, prospective one-day pointprevalence study conducted in 13 ICUs of six countries demonstrated that IAH was present in $>50 \%$ of all surgical and medical critically ill patients hospitalized for $>$ $24 \mathrm{~h}$ [9]. Interestingly, we found that most patients with spontaneous bacterial peritonitis $(64 \%)$ had normal IAP. This may be explained by the fact that these patients might have undergone therapeutic and diagnostic abdominal paracentesis before ICU admission.
Whether IAH is a marker of illness severity or a cause of critical illness or clinical deterioration remains unclear. Malbrain et al. found that the development of IAH during ICU stay, and not IAH at ICU admission, was a risk factor for mortality in a general population of critically ill patients [16]. In our study, IAH on admission was associated with a higher APACHE II score but was also a strong independent predictor of the need for RRT and ICU mortality on multivariate logistic regression analysis. The potential pathophysiologic changes responsible for these effects are multiple. Various organs, inside and outside the abdomen, can be adversely affected by increased IAP [12]. For example, IAH is associated with increased intracranial pressure [29], cardiac dysfunction [30], respiratory failure [31], splanchnic hypoperfusion [13] and acute renal insufficiency [32]. These are probably the results of mechanical and nonmechanical effects of increased IAP [33]. In association with massive fluid resuscitation, the acute intestinal permeability syndrome, which is part of global 
Table 3 Stepwise multivariate logistic regression analysis for three outcomes: mortality in the ICU, hospital and need for RRT.

\begin{tabular}{|c|c|c|c|c|c|}
\hline \multirow[t]{2}{*}{ Variable } & \multicolumn{2}{|c|}{ Intra-abdominal hypertension } & \multirow[t]{2}{*}{ Variable } & \multicolumn{2}{|c|}{ Abdominal hypoperfusion } \\
\hline & Odds ratio & 95\% Confidence interval & & Odds ratio & 95\% Confidence interval \\
\hline \multicolumn{6}{|l|}{ ICU mortality } \\
\hline Intra-abdominal hypertension & 12.20 & 1.92 to 77.31 & Abdominal hypoperfusion & 2.86 & 0.74 to 11.11 \\
\hline Age & 1.02 & 0.97 to 1.08 & Age & 0.98 & 0.92 to 1.04 \\
\hline \multirow[t]{2}{*}{ INR } & 3.60 & 1.29 to 10.06 & INR & 2.67 & 1.02 to 7.00 \\
\hline & & & APACHE II score & 1.14 & 1.02 to 1.26 \\
\hline \multicolumn{6}{|l|}{ Hospital mortality } \\
\hline Intra-abdominal hypertension & 6.83 & 0.86 to 54.12 & Abdominal hypoperfusion & 2.44 & 0.38 to 6.67 \\
\hline Age & 1.07 & 0.99 to 1.17 & Age & 1.05 & 0.97 to 1.14 \\
\hline \multirow[t]{2}{*}{ INR } & 6.2 & 1.07 to 38.5 & INR & 6.36 & 0.92 to 44.22 \\
\hline & & & APACHE II score & 1.11 & 0.98 to 1.26 \\
\hline \multicolumn{6}{|l|}{ Renal replacement therapy } \\
\hline Intra-abdominal hypertension & 6.78 & 1.29 to 35.70 & Abdominal hypoperfusion & 2.78 & 0.68 to 11.11 \\
\hline Age & 0.92 & 0.92 to 1.04 & Age & 0.96 & 0.90 to 1.02 \\
\hline INR & 2.06 & 0.98 to 4.32 & APACHE & 1.14 & 1.04 to 1.25 \\
\hline Child-Pugh score & 0.51 & 0.30 to 0.90 & Child-Pugh score & 0.63 & 0.40 to 0.98 \\
\hline Creatinine & 1.00 & 1.00 to 1.01 & & & \\
\hline
\end{tabular}

Variables used in the model were age, Child-Pugh score, Acute Physiology and Chronic Health Evaluation II score, creatinine, INR, fluid balance on day 1 , hydrocortisone therapy and either the presence of intra-abdominal hypertension (mean intra-abdominal pressure $\geq 12 \mathrm{vs}$. $<12 \mathrm{mmHg}$ ) or abdominal hypoperfusion (mean abdominal perfusion pressure $<60 \mathrm{vs} . \geq 60 \mathrm{mmHg}$ ) on first ICU admission day. Variables with $p<0.1$ on stepwise multivariate logistic regression analysis are reported in the table. APACHE, Acute Physiology and Chronic Health Evaluation; INR, international normalized ratio; RRT, renal replacement therapy.

capillary leak, may lead to multi-organ failure [33]. In addition, IAH is associated with a proinflammatory state [28]. In a study of ten rats, IAH of $20 \mathrm{mmHg}$ caused a significant increase in tumor necrosis factor $\alpha$ and interleukin- 6 after 30 min and an increase in interleukin-1b after $60 \mathrm{~min}$ [28]. This state may serve as a second insult for the development of multiple organ failure. Of note, IAH was significantly associated with ICU, but not hospital mortality. Explanations include that ICU survivors had advanced cirrhosis and died later during hospitalization because of disease progression with or without Do-Not-Resuscitate orders, or did not receive liver transplantation because of organ shortage or being unfit. Additionally, because our study included the first ICU admission only, the ICU mortality represents the first ICU admission mortality, while hospital mortality includes mortality during all ICU admissions and ward admissions.

Because of the adverse effects of IAH on various organs, lowering IAP and using APP as a resuscitation endpoint appear to be appealing management strategies. A retrospective study of 144 surgical patients treated for IAH (IAP $\geq 15 \mathrm{mmHg}$ ) with resuscitation and, if needed, with open abdominal decompression surgery found that APP was able to discriminate survivors from nonsurvivors better than MAP and lactate [34]. In our study, the ROC curves showed that IAP and APP, but not MAP or $\mathrm{ScvO}_{2}$, predicted survival, raising the question whether
IAP and APP are better resuscitative endpoints than the traditional ones. The ROC curve analysis also suggested that IAP $<12 \mathrm{mmHg}$ and APP $>55 \mathrm{mmHg}$ should be considered therapeutic targets in cirrhotics with SS. Additionally, we found that, in most patients in whom traditional resuscitative endpoints were achieved (MAP $\geq$ $\left.65 \mathrm{mmHg}, \mathrm{ScvO}_{2} \geq 70 \%\right)$, IAP and APP were not. Achieving the target MAP and $\mathrm{ScvO}_{2}$ alone might not be enough in this population.

IAH management is recommended in critically ill patients [24] even though strong evidence of its benefit remains lacking. A prospective observational study of 478 consecutive surgical patients requiring an open abdomen for the management of IAH or ACS showed a significant decrease in hospital mortality after the implementation of a comprehensive management algorithm for IAH and ACS [35]. In 23 cirrhotic patients with hepatorenal syndrome, infusion of $200 \mathrm{ml}$ of $20 \%$ human albumin solution followed by large-volume abdominal paracentesis resulted in IAP reduction from a median of 22 to $9 \mathrm{mmHg}$ and a significant increase in creatinine clearance during the subsequent $12 \mathrm{~h}$ from 23 $\mathrm{ml} / \mathrm{min}$ to $33 \mathrm{ml} / \mathrm{min}(p=0.002)$ [36]. Moreover, creatinine clearance remained elevated for up to several days afterwards [36]. Medical interventions that have been suggested to treat IAH include sedation, neuromuscular blockade, gastric or colonic decompression, hypertonic fluids or colloids, forced diuresis and hemofiltration 


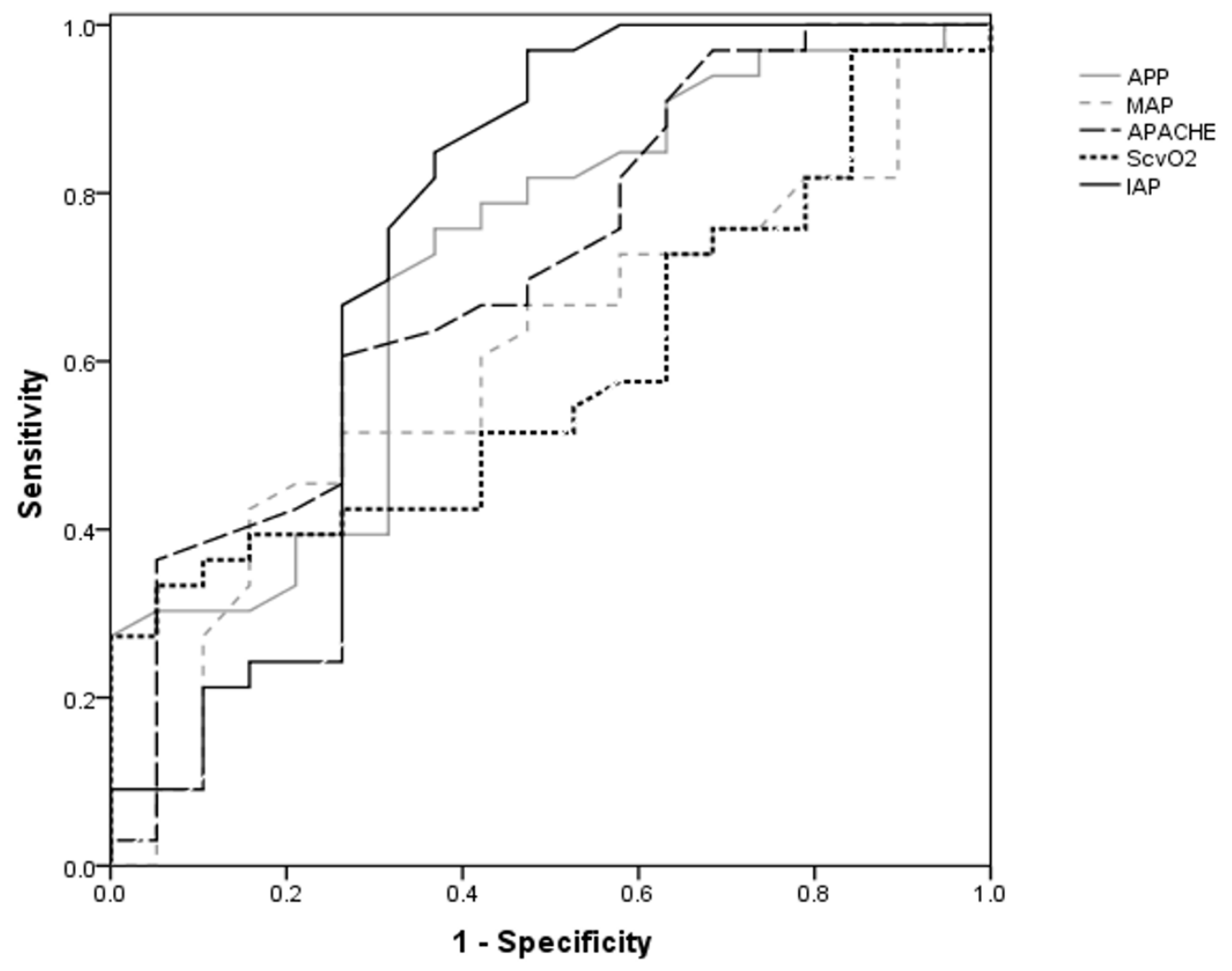

\begin{tabular}{|l|l|l|l|}
\hline Variable & AUC & P value & $95 \%$ CI \\
\hline $\begin{array}{l}\text { APACHE } \\
\text { II }\end{array}$ & 0.71 & 0.02 & $0.56-0.85$ \\
\hline MAP & 0.60 & 0.24 & $0.44-0.76$ \\
\hline ScvO $_{2}$ & 0.59 & 0.30 & $0.43-0.74$ \\
\hline IAP & 0.74 & 0.004 & $0.58-0.90$ \\
\hline APP & 0.71 & 0.01 & $0.56-0.85$ \\
\hline
\end{tabular}

Figure 3 Receiver operating characteristic curve analysis for predictors of intensive care unit mortality. The variables studied are Acute Physiology and Chronic Health Evaluation (APACHE) II score, mean arterial pressure, central venous oxygen saturation, intra-abdominal pressure and abdominal perfusion pressure. These variables, except for APACHE II score, were the mean of measurements taken every $6 \mathrm{~h}$ on the first admission day to the intensive care unit.

with ultrafiltration [24]. Supporting organ function with vasopressors and judicious goal-directed fluid resuscitation to maintain an APP $\geq 50$ to $60 \mathrm{mmHg}$ has also been advocated [24,35]. More invasive procedures including percutaneous catheter decompression or drainage and surgical decompression might be helpful, especially when IAP exceeds $25 \mathrm{mmHg}$ [35]. Our study did not assess the physiologic effects of interventions such 


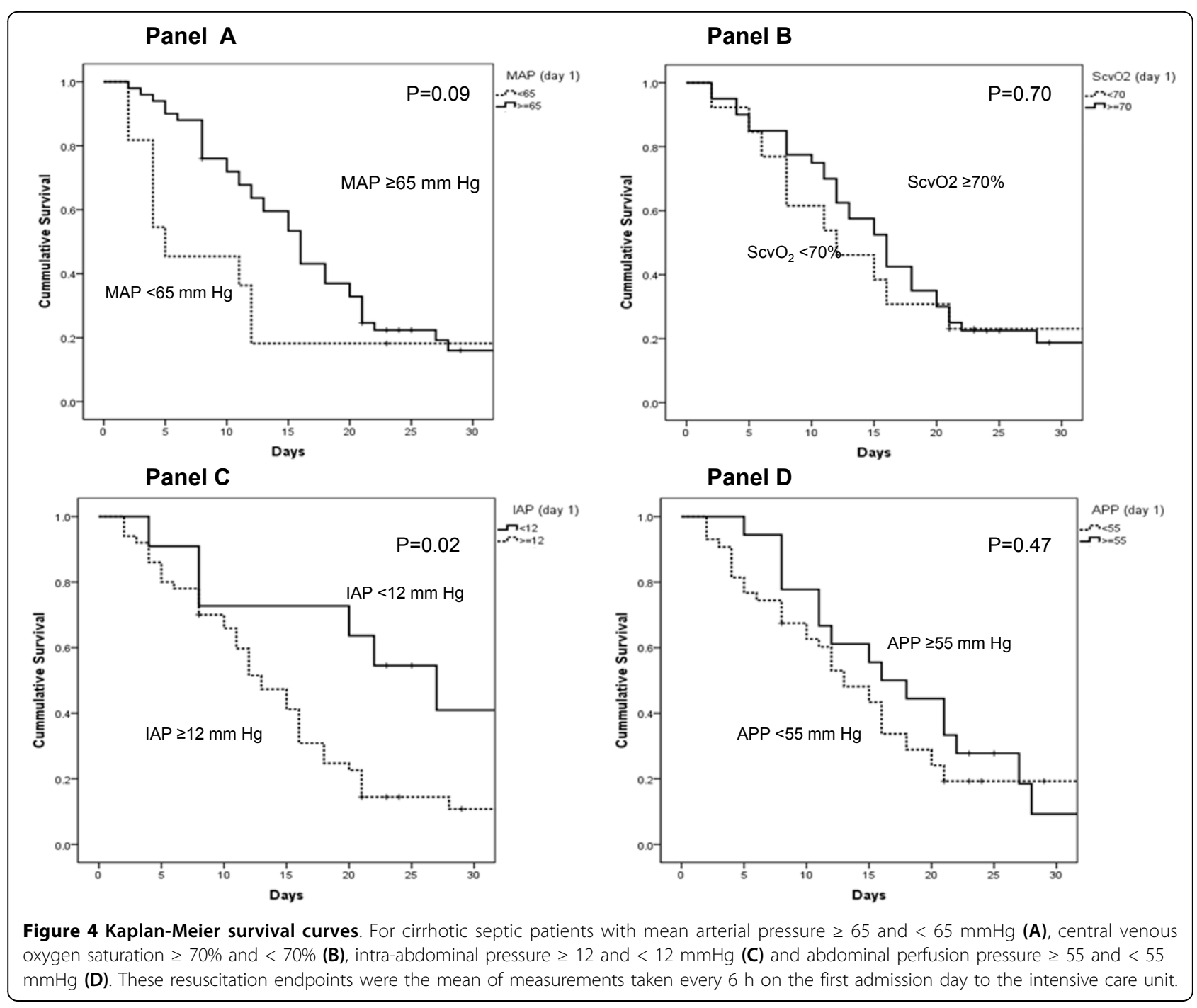

as abdominal paracentesis or the prognostic implications of IAH management.

Our findings should be interpreted in the light of the strengths and limitations of the study. Strengths include the prospective data collection, the IAP measurements every $6 \mathrm{~h}$ by trained critical care nurses and the clearly defined clinical outcomes. However, there are some limitations. First, it was a single-center retrospective study. Second, it had a small sample size. Nevertheless, our patient population, cirrhotic patients with SS, is interesting and merits additional research. Third, it lacked data on the effect of ascites evacuation. Fourth, the intra-vesicular pressure was measured using 50 to $100 \mathrm{ml}$ of sterile saline, which is too large and has been shown to overestimate intra-vesicular pressure $[37,38]$. The current recommendation is to use a maximum of $25 \mathrm{ml}$ [23]; however, the study began before such a recommendation was published. Fifth, the use of the symphysis pubis as the zero reference point is outdated. It is currently recommended to zero the transducer at the mid-axillary line level $[23,39]$. Although the study was conducted over a relatively long period (2004 to 2007), clinical management was standardized and followed a strict study protocol and, therefore, unlikely to have affected outcomes.

In conclusion, IAH was at least a marker of increased ICU morbidity and mortality in cirrhotic patients with SS. Based on the physiologic effects of increased IAP, IAH might even be a contributing factor to the development of organ dysfunction and death in them. Whether the IAH management improves the outcome of this patient population needs to be further studied in a randomized controlled trial. This future research is especially important considering that the prognosis of cirrhotic patients who develop critical illness remains poor despite aggressive therapy and advances in intensive care. 


\section{List of abbreviations}

ACS: abdominal compartment syndrome; APACHE: Acute Physiology and Chronic Health Evaluation; APP: abdominal perfusion pressure; Cl: confidence interval; CVP: central venous pressure; IAP: intra-abdominal pressure; IAH: intra-abdominal hypertension; INR: international normalized ratio; MAP: mean arterial pressure; OR: odds ratio; ROC: receiver operating characteristic; RRT: renal replacement therapy; $\mathrm{ScvO}_{2}$ : central venous oxygen saturation; SD: standard deviation; SOFA: Sequential Organ Failure Assessment; SS: septic shock; WSACS: World Society on Abdominal Compartment Syndrome.

\section{Acknowledgements}

This article has been published as part of Annals of Intensive Care Volume 2 Supplement 1, 2012: Diagnosis and management of intra-abdominal hypertension and abdominal compartment syndrome. The full contents of the supplement are available online at http://www.annalsofintensivecare. com/supplements/2/S1

\section{Author details}

'Department of Intensive Care Medicine, King Saud bin Abdulaziz University for Health Sciences, King Abdulaziz Medical City, Riyadh, 11426, Saudi Arabia. ${ }^{2}$ Department of Epidemiology and Biostatistics, King Saud bin Abdulaziz University for Health Sciences, King Abdulaziz Medical City, Riyadh, 11426, Saudi Arabia. ${ }^{3}$ Department of Hepatobiliary Sciences and Liver Transplantation, King Saud bin Abdulaziz University for Health Sciences, King Abdulaziz Medical City, Riyadh, 11426, Saudi Arabia.

\section{Authors' contributions}

HMA conceived and designed the study, analyzed and interpreted the data and drafted the manuscript. HMT and AHR acquired and analyzed the data and made revisions in the manuscript. AA interpreted the data and made revisions in the manuscript. YMA, the principal investigator of the original trial, conceived and designed the study, interpreted data and drafted the manuscript. All authors made critical revisions, have read and approved the final manuscript.

\section{Authors' information}

HMA, MD is an Intensive Care Medicine consultant at King Abdulaziz Medical City and an assistant professor of the College of Medicine, King Saud bin Abdulaziz University for Health Sciences. HMT, MPH, PhD is an associate professor of Epidemiology and Biostatistics at the College of Medicine, King Saud bin Abdulaziz University for Health Sciences. AHR, MBBS is a research coordinator of the Intensive Care Department at King Abdulaziz Medical City. AA, MD is the division head and consultant of the Hepatobiliary Sciences and Liver Transplantation division of King Abdulaziz Medical City and an assistant professor of the College of Medicine, King Saud bin Abdulaziz University for Health Sciences. YMA, MD, FCCP, FCCM is the Intensive Care Department chairman of King Abdulaziz Medical City and an associate professor of the College of Medicine, King Saud bin Abdulaziz University for Health Sciences.

\section{Competing interests}

The authors declare that they have no competing interests.

Published: 5 July 2012

\section{References}

1. Moreau R, Hadengue A, Soupison T, Kirstetter P, Mamzer MF, Vanjak D, Vauquelin P, Assous M, Sicot C: Septic shock in patients with cirrhosis: hemodynamic and metabolic characteristics and intensive care unit outcome. Crit Care Med 1992, 20(6):746-750

2. Zimmerman JE, Wagner DP, Seneff MG, Becker RB, Sun X, Knaus WA: Intensive care unit admissions with cirrhosis: risk-stratifying patient groups and predicting individual survival. Hepatology 1996, 23(6):1393-1401.

3. Singh N, Gayowski T, Wagener MM, Marino IR: Outcome of patients with cirrhosis requiring intensive care unit support: prospective assessment of predictors of mortality. J Gastroenterol 1998, 33(1):73-79.

4. Kress JP, Rubin A, Pohlman AS, Hall JB: Outcomes of critically ill patients denied consideration for liver transplantation. Am J Respir Crit Care Med 2000, 162(2 Pt 1):418-423.
5. Aggarwal A, Ong JP, Younossi ZM, Nelson DR, Hoffman-Hogg L, Arroliga AC: Predictors of mortality and resource utilization in cirrhotic patients admitted to the medical ICU. Chest 2001, 119(5):1489-1497.

6. Arabi Y, Ahmed QA, Haddad S, Aljumah A, Al-Shimemeri A: Outcome predictors of cirrhosis patients admitted to the intensive care unit. Eur J Gastroenterol Hepatol 2004, 16(3):333-339.

7. Gines P, Quintero E, Arroyo V, Teres J, Bruguera M, Rimola A, Caballeria J, Rodes J, Rozman C: Compensated cirrhosis: natural history and prognostic factors. Hepatology 1987, 7(1):122-128.

8. Navasa M, Casafont F, Clemente G, Guarner C, de la Mata M, Planas R, Sola R, Suh J: Consensus on spontaneous bacterial peritonitis in liver cirrhosis: diagnosis, treatment, and prophylaxis. Gastroenterol Hepatol 2001, 24(1):37-46.

9. Malbrain ML, Chiumello D, Pelosi P, Wilmer A, Brienza N, Malcangi V, Bihari D, Innes R, Cohen J, Singer P, Japiassu A, Kurtop E, De Keulenaer BL, Daelemans R, Del Turco M, Cosimini P, Ranieri M, Jacquet L, Laterre PF, Gattinoni L: Prevalence of intra-abdominal hypertension in critically ill patients: a multicentre epidemiological study. Intensive Care Med 2004, 30(5):822-829.

10. Vidal MG, Ruiz Weisser J, Gonzalez F, Toro MA, Loudet C, Balasini C, Canales H, Reina R, Estenssoro E: Incidence and clinical effects of intraabdominal hypertension in critically ill patients. Crit Care Med 2008, 36(6):1823-1831.

11. Richards WO, Scovill W, Shin B, Reed W: Acute renal failure associated with increased intra-abdominal pressure. Ann Surg 1983, 197(2):183-187.

12. Cullen DJ, Coyle JP, Teplick R, Long MC: Cardiovascular, pulmonary, and renal effects of massively increased intra-abdominal pressure in critically ill patients. Crit Care Med 1989, 17(2):118-121.

13. Caldwell CB, Ricotta JJ: Changes in visceral blood flow with elevated intraabdominal pressure. J Surg Res 1987, 43(1):14-20.

14. Barnes GE, Laine GA, Giam PY, Smith EE, Granger HJ: Cardiovascular responses to elevation of intra-abdominal hydrostatic pressure. Am J Physiol 1985, 248(2 Pt 2):R208-213.

15. Malbrain ML: Is it wise not to think about intraabdominal hypertension in the ICU? Curr Opin Crit Care 2004, 10(2):132-145.

16. Malbrain ML, Chiumello D, Pelosi P, Bihari D, Innes R, Ranieri VM, Del Turco M, Wilmer A, Brienza N, Malcangi V, Cohen J, Japiassu A, De Keulenaer BL, Daelemans R, Jacquet L, Laterre PF, Frank G, de Souza P, Cesana B, Gattinoni L: Incidence and prognosis of intraabdominal hypertension in a mixed population of critically ill patients: a multiplecenter epidemiological study. Crit Care Med 2005, 33(2):315-322.

17. Luca A, Cirera I, Garcia-Pagan JC, Feu F, Pizcueta P, Bosch J, Rodes J: Hemodynamic effects of acute changes in intra-abdominal pressure in patients with cirrhosis. Gastroenterology 1993, 104(1):222-227.

18. Knaus WA, Draper EA, Wagner DP, Zimmerman JE: APACHE II: a severity of disease classification system. Crit Care Med 1985, 13(10):818-829.

19. Arabi YM, Aljumah A, Dabbagh O, Tamim HM, Rishu AH, Al-Abdulkareem A, Knawy BA, Hajeer AH, Tamimi W, Cherfan A: Low-dose hydrocortisone in patients with cirrhosis and septic shock: a randomized controlled trial. CMAJ 2010, 182(18):1971-1977.

20. Fusco MA, Martin RS, Chang MC: Estimation of intra-abdominal pressure by bladder pressure measurement: validity and methodology. I Trauma 2001, 50(2):297-302.

21. Cheatham ML, Safcsak K: Intraabdominal pressure: a revised method for measurement. J Am Coll Surg 1998, 186(5):594-595.

22. Rivers E, Nguyen B, Havstad S, Ressler J, Muzzin A, Knoblich B, Peterson E, Tomlanovich M: Early goal-directed therapy in the treatment of severe sepsis and septic shock. N Engl J Med 2001, 345(19):1368-1377.

23. Malbrain ML, Cheatham ML, Kirkpatrick A, Sugrue M, Parr M, De Waele J, Balogh Z, Leppaniemi A, Olvera C, Ivatury R, D'Amours S, Wendon J, Hillman K, Johansson K, Kolkman K, Wilmer A: Results from the International Conference of Experts on Intra-abdominal Hypertension and Abdominal Compartment Syndrome. I. Definitions. Intensive Care Med 2006, 32(11):1722-1732.

24. Cheatham ML, Malbrain ML, Kirkpatrick A, Sugrue M, Parr M, De Waele J, Balogh Z, Leppaniemi A, Olvera C, Ivatury R, D'Amours S, Wendon J, Hillman K, Wilmer A: Results from the International Conference of Experts on Intra-abdominal Hypertension and Abdominal Compartment Syndrome. II. Recommendations. Intensive Care Med 2007, 33(6):951-962. 
25. Ferreira FL, Bota DP, Bross A, Melot C, Vincent JL: Serial evaluation of the SOFA score to predict outcome in critically ill patients. JAMA 2001, 286(14):1754-1758.

26. Bewick V, Cheek L, Ball J: Statistics review 13: receiver operating characteristic curves. Critical care 2004, 8(6):508-512.

27. Escorsell A, Gines A, Llach J, Garcia-Pagan JC, Bordas JM, Bosch J, Rodes J: Increasing intra-abdominal pressure increases pressure, volume, and wall tension in esophageal varices. Hepatology 2002, 36(4 Pt 1):936-940.

28. Rezende-Neto JB, Moore EE, Melo de Andrade MV, Teixeira MM, Lisboa FA, Arantes RM, de Souza DG, da Cunha-Melo JR: Systemic inflammatory response secondary to abdominal compartment syndrome: stage for multiple organ failure. J Trauma 2002, 53(6):1121-1128.

29. De laet I, Citerio G, Malbrain ML: The influence of intraabdominal hypertension on the central nervous system: current insights and clinical recommendations, is it all in the head? Acta Clin Belg Suppl 2007, 1: 89-97.

30. Cheatham ML, Malbrain ML: Cardiovascular implications of abdominal compartment syndrome. Acta Clin Belg Suppl 2007, , 1: 98-112.

31. Pelosi P, Quintel M, Malbrain ML: Effect of intra-abdominal pressure on respiratory mechanics. Acta Clin Belg Suppl 2007, , 1: 78-88.

32. De laet I, Malbrain ML, Jadoul JL, Rogiers P, Sugrue M: Renal implications of increased intra-abdominal pressure: are the kidneys the canary for abdominal hypertension? Acta Clin Belg Suppl 2007, , 1: 119-130.

33. Malbrain ML, De Laet I: AIDS is coming to your ICU: be prepared for acute bowel injury and acute intestinal distress syndrome. Intensive Care Med 2008, 34(9):1565-1569.

34. Cheatham ML, White MW, Sagraves SG, Johnson JL, Block EF: Abdominal perfusion pressure: a superior parameter in the assessment of intraabdominal hypertension. J Trauma 2000, 49(4):621-627.

35. Cheatham ML, Safcsak K: Is the evolving management of intra-abdominal hypertension and abdominal compartment syndrome improving survival? Crit Care Med 2010, 38(2):402-407.

36. Umgelter A, Reindl W, Wagner KS, Franzen M, Stock K, Schmid RM, Huber W: Effects of plasma expansion with albumin and paracentesis on haemodynamics and kidney function in critically ill cirrhotic patients with tense ascites and hepatorenal syndrome: a prospective uncontrolled trial. Crit Care 2008, 12(1):R4.

37. Malbrain ML, Deeren DH: Effect of bladder volume on measured intravesical pressure: a prospective cohort study. Crit Care 2006, 10(4) R98.

38. De laet I, Hoste E, De Waele JJ: Transvesical intra-abdominal pressure measurement using minimal instillation volumes: how low can we go? Intensive Care Med 2008, 34(4):746-750.

39. Cheatham ML, De Waele JJ, De Laet I, De Keulenaer B, Widder S, Kirkpatrick AW, Cresswell AB, Malbrain M, Bodnar Z, Mejia-Mantilla JH, Reis R, Parr M, Schulze R, Puig S: The impact of body position on intraabdominal pressure measurement: a multicenter analysis. Critical care medicine 2009, 37(7):2187-2190.

doi:10.1186/2110-5820-2-S1-S4

Cite this article as: Al-Dorzi et al: Intra-abdominal pressure and abdominal perfusion pressure in cirrhotic patients with septic shock Annals of Intensive Care 2012 2(Suppl 1):S4.

\section{Submit your manuscript to a SpringerOpen ${ }^{\circ}$ journal and benefit from:}

- Convenient online submission

- Rigorous peer review

- Immediate publication on acceptance

- Open access: articles freely available online

- High visibility within the field

- Retaining the copyright to your article

Submit your next manuscript at $\gg$ springeropen.com 